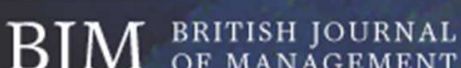

\section{Job seekers with musculoskeletal or sensory disabilities:} Barriers and facilitators of job search

\begin{tabular}{|c|c|}
\hline Journal: & British Journal of Management \\
\hline Manuscript ID & BJM-17-035.R2 \\
\hline Manuscript Type: & Original Article \\
\hline Keywords: & $\begin{array}{l}\text { Job search, People with disabilities, Recruitment, Selection, Barriers, } \\
\text { Support }\end{array}$ \\
\hline $\begin{array}{l}\text { Primary Special Interest Group } \\
\text { (SIG): }\end{array}$ & Human Resource Management \\
\hline $\begin{array}{r}\text { Secondary Special Interest } \\
\text { Group (SIG): }\end{array}$ & None \\
\hline
\end{tabular}


Job seekers with disabilities 1

\title{
JOB SEEKERS WITH MUSCULOSKELETAL OR SENSORY DISABILITIES: BARRIERS AND FACILITATORS OF JOB SEARCH
}

\begin{abstract}
Drawing on interviews with job seekers and expert informants, we outline a model of the job search experience of people with disabilities. This model outlines the sequence of events involved in the pursuit of paid work and the contextual features that inhibit or facilitate job search attitudes, behaviours, intermediate search outcomes, and employment outcomes. By contrasting the experiences of job seekers with musculoskeletal and sensory disabilities, and outlining the influence of major stakeholders in the form of employment agencies and family members, our model provides the basis for a more nuanced understanding of the job search process. Finally, we recommend points of intervention that are grounded in data for improving job search outcomes for people with disabilities in general, and for job seekers with musculoskeletal or sensory disabilities specifically.
\end{abstract}

\author{
Key words \\ Job search, People with disabilities, Recruitment, Selection, Barriers, Support
}


Job seekers with disabilities 2

People with disabilities face significant barriers when searching for employment. These barriers contribute to exclusion from paid work roles (WHO, 2011). For example, job seekers with disabilities describe overt and subtle employment discrimination and are less likely to gain a job even after controlling for human capital factors such as education, job relevant knowledge, and social skills (Hall and Parker, 2010). Even when they do obtain employment, difficulties encountered in finding a job translate into lower quality and less rewarding work (Villanueva-Flores, Valle and Bornay-Barrachina, 2017). This is reflected in the disproportionate number of people with disabilities who are underemployed (ABS, 2012). These individuals work fewer hours, are relatively underpaid, and are overrepresented in semi or unskilled occupations and home based work (ABS, 2012; Burchardt, 2000; Konrad et al., 2013).

Job search barriers faced by people with disabilities have real costs than are borne by individuals, organisations, and society. For people with disabilities, unemployment or underemployment contributes to financial pressure and lower self-esteem that threatens health and social relationships (Paul and Moser, 2009; Konrad et al., 2013). It also leads to a loss of employable skills and to negative beliefs about one's ability to obtain future work (Layard, Nickell and Jackman, 1994). More broadly, organisations and society suffer when people with disabilities become discouraged from seeking employment. This discouragement depresses workforce participation, reducing the pool of potential job applicants for organisations, and increasing social welfare obligations. Yet, despite their growing importance in the labour market, organisational researchers are yet to provide a systematic investigation of how of people with disabilities progress through the multistage process of searching for work.

Job search researchers have historically focused on the experience of relatively homogeneous samples of white, university educated professionals or students (Wanberg, 
Basbug, Van Hooft and Samtani, 2012a; Van Hooft, Born, Taris and Van der Flier, 2005). This is problematic as it is increasingly apparent that job seekers with disabilities have a distinct experience. For example, recent studies illustrate how job seekers with disabilities use unique job search pathways offered by government disability employment agencies (Kulkarni and Scullion, 2015), rely on qualitatively different personal networks (Dimakos et al., 2016; Langford, Lengnick-Hall and Kulkarni, 2013; Petner-Arrey, Howell-Moneta and Lysaght, 2016), and face distinct social expectations about their abilities (Jammaers, Zanoni and Hardonk, 2016; Baldridge and Kulkarni, 2017). Despite this growing interest, the process by which job seekers move from initial dispositional states to employment offers, and the roles of employment agencies, family, and disability type in that process are yet to be fully elaborated. For example, while researchers have outlined how disability employment agencies (Kulkarni and Scullion, 2015) and social network characteristics (Langford et al., 2013) influence the likelihood of gaining employment, they did not examine the role of these factors in the initial stages of search where job seeker dispositions, attitudes and behaviours are central issues. Other researchers have considered the experiences of people with different types of disability (Baldridge et al., 2016) but with a focus on workplace rather than job search experiences.

To address this research gap, we conducted 31 in-depth interviews with job seekers with disabilities and key stakeholders relevant to them. Based upon an inductive analysis of these interview data, we develop a process model that shows how people with disabilities progress through the multiple stages of searching for paid work. This model represents major features that impede or facilitate the likelihood of progression through the job search process. More broadly, we outline how stakeholders convey the influence of these features and thus shape the likelihood of successful job search. 
Job seekers with disabilities 4

This study provides four contributions to research and practice. First, researchers typically focus on barriers to job seekers with disabilities that occur at the selection stage (e.g., interviewing - Araten-Bergman, 2016; Cavanagh et al., 2016). We extend this by drawing upon a process perspective which characterises job search as a sequential pattern of activities (Kanfer, Wanberg and Kantrowitz, 2001; Wanberg, Zhu and Van Hooft, 2010; Wanberg, Zhu, Kanfer and Zhang, 2012b). In doing so, we shed light on understudied but crucial early stages of the job search process. Second, we extend the job search literature by examining how stakeholders impede or facilitate access to resources and thus shape the employment outcomes for job seekers with disabilities. Our data provide insight into the role of influential stakeholders in the form of disability employment and training agencies and family members. Third, we outline how disability type shapes job search experiences by contrasting people with musculoskeletal and sensory disabilities. This directly addresses Kulkarni and Scullion's (2015) call for research that identifies the support that is most helpful for job seekers with these two common types of disabilities. Fourth, our model reveals how organisations and policymakers can improve employment outcomes via specific interventions that benefit job seekers and improve stakeholder effectiveness. In particular, our findings concerning the role of stakeholders and disability type broaden the range of possible approaches for improving the job search outcomes of people with disabilities.

\section{THEORETICAL CONTEXT}

\section{The job search process}

Job search is an intentional and dynamic self-regulatory process of goal-directed behaviour undertaken with the aim of obtaining employment (Kanfer et al., 2001; Song, Wanberg, Niu and Xie, 2006). Extant job search theories (Blau, 1993; Osborn, 1990; 
Soelberg, 1967) suggest that job search occurs in stages with self-regulation theories (Bandura, 1989; Kanfer and Kanfer 1991) holding that job search, as a self-managing pattern of behaviour, begins with individuals' commitment to pursue an employment goal (Kanfer et al., 2001; Wanberg et al., 2010; Wanberg et al., 2012b). In relation to antecedent variables, Kanfer et al.'s (2001) review of the job search literature identifies several personal characteristics (i.e., personality traits, optimism, locus of control, selfevaluations, motives, demographics) that contribute to job search behaviour. Job seekers with a more conscientious personality (Wanberg, Watt and Rumsey, 1996), greater job search self-efficacy (Brown et al., 2006), and greater human capital (Wanberg, Hough and Song, 2002) undertake more search behaviours. In turn, these job search behaviours (e.g., job applications) contribute to intermediate job search outcomes (e.g., job interviews) and employment outcomes (e.g., job offers) (Kanfer et al., 2001). Finally, the dynamic nature of the job search process is considered in research on feedback processes in the job search process which, via Control Theory (Carver, 2003, 2006) and Social Cognitive Theory (Bandura, 1986, 1977), outline how individuals self-regulate effort following positive or negative feedback on their job search performance. An illustration of this is Wanberg et al. (2012b) who explored the role of self-regulatory states in shaping responses to positive and negative job search outcomes (see also, Wanberg et al., 2010). In summary, this extensive literature delineates the core process by which people search for employment (for reviews, see Manroop and Richardson, 2016; Kanfer et al., 2001; Boswell, Zimmerman and Swider, 2012; Saks, 2005). In our study, we elaborate upon this core job search process by exploring issues that affect how job seekers with disabilities progress (or fail to progress) through it.

\section{Job seekers with disabilities}


Job seekers with disabilities 6

Job seekers with disabilities also progress through the same sequential process of looking for employment in which job dispositions and attitudes set the scene for behaviours that are the precursors to interview and job offers (e.g., Szymanski and Parker, 2003; Ryan, 2011; Jans, Kaye and Jones, 2012). However, while the core process of searching for employment is consistent for people with and without disabilities, both disability theory and empirical research suggest that experiences at each stage of the process diverge. For example, the social model of disability (Barnes and Mercer, 2004) provides a useful overarching framework for conceptualising and understanding the disability experience. The social model of disability defines disability as a physical and/or mental impairment created by one's situation that limits major life activities (Bruyère and James, 1997). Disability is thus understood as an outcome of societal processes, involving power, social attitudes, social structure and social relations. This is consistent with organisational theories including social identity theory (Tajfel and Turner, 1979) and the disability stigmatization model (Stone \& Colella, 1996) that outline the motivational basis for the categorisation and stereotyping of people with disabilities and that link these psychological processes to the creation of barriers to employment participation.

These related theoretical perspectives suggest that unfavourable societal beliefs about disability should lead to adverse experiences for job seekers. Consistent with this, people with disabilities are found to experience a disabling societal context when seeking employment that creates barriers to obtaining high quality work (Kulkarni and LengnickHall, 2014; Cunningham, James and Dibben, 2004; Cregan, Kulik and Bainbridge, in press). For example, people with disabilities navigate unique issues when motivating themselves to apply for employment (e.g., internalisation of stigma), in job applications (e.g., whether to disclose a disability), and during job interviews (e.g., disability employment stereotypes). However, there is little organisational research on the features 
that impede or facilitate progression through job search stages for people with disabilities. This gap is especially apparent for early stages of job search (Ali, Schur and Blanck, 2011). Research is needed that provides a comprehensive account of the barriers and facilitators to looking for work that spans the entire job search process.

\section{Stakeholders in the job search process}

Organisational research has tended to emphasise the study of individual characteristics in the job search process. This focus on the job seeker is reflected in the emphasis placed on self-regulatory processes to explain a job seeker's acquisition of the resources needed to identify and obtain work. By contrast, the social context in which job search is undertaken has received less attention (Boswell et al., 2012). Accordingly, extant research gives only a partial view of why job seekers succeed or fail in their quest for high quality work.

Job search context is important because it is clear that people with disabilities also obtain needed resources via their interpersonal networks. Network members provide support directly to job seekers but also function as intermediaries (Barber, Daly, Giannantonio and Phillips, 1994), acting as a conduit for resources from others who are not directly connected to the job seeker. For this reason, researchers are increasingly focusing on the social structure surrounding a job seeker with disabilities and the role of key actors in this interpersonal network (e.g., Kulkarni, 2012; Kulkarni and Gopakumar, 2014; Potts, 2005). For example, researchers have considered how job search outcomes are influenced by contact with trade unions (Richards and Sang, 2016), community organisations (Fujimoto et al., 2014), and others with disabilities (Kulkarni and Gopakumar, 2014). Recent studies also explore how connections with health professionals and friends (Dimakos et al., 2016), or neighbours (Waverijn, Heijmans and 
Job seekers with disabilities 8

Groenewegen, 2017) affect the social resources of people with disabilities.

Social network theory holds that the social structure in which an individual is embedded shapes the job search process (Granovetter, 1974; Montgomery, 1991). In particular, social network characteristics such as homophily (Ibarra, 1992), tie strength (Smith, 2000), and centrality (Brass, 1985) affect the employment and career outcomes of minorities. Homophily refers to the tendency of individuals to associate with others who have a similar identity or characteristics (McPherson, Smith-Lovin and Cook, 2001). Tie strength is defined as the degree of closeness of the interaction between two individuals (Granovetter, 1973) and betweenness centrality denotes the extent to which a person occupies a network position that connects two individuals (Freeman, 1979).

Langford et al. (2013) drew upon these themes to argue that homophily, tie strength, and centrality are particularly influential network characteristics for job seekers with disabilities. Accordingly, there appears to be a strong rationale for exploring whether job seekers with disabilities benefit from access to stakeholders with high values of these network characteristics. Who are these stakeholders? Two groups seem especially interesting: Disability employment and training agency (DETA) advisors, and family members. Both DETA advisors and family develop strong ties to a job seeker though regular interactions and/or kin relationships. Each has commonalities of experience with the job seeker via their familiarity with disability. Each is also likely to be an influential part of a job seeker's interpersonal network because DETA advisors and family are more likely to be centrally located between the job seeker and job relevant contacts (Dimakos et al., 2016). However, despite their potential importance, the influence of these stakeholders across the multi-stage job search process has received limited study. We thus focus on these two crucial but underexamined stakeholders in the following material.

Disability employment and training agencies. In North America, Europe, and 
Job seekers with disabilities 9

Australia, governments have sought to improve employment outcomes of job seekers by funding disability employment and training agencies (DETA). Advisors working in a DETA operate as an intermediary between the job seeker and employers, government agencies, and other job seekers with disabilities. DETA help job seekers with disabilities to look for a job and assist with efforts to find and keep a job. They supply job skills training, assistance with gaining qualifications, help with resume writing and interview technique, facilities for searching for work, and information on job opportunities. They also provide access to financial support for work modifications and assistive technologies. For employers, DETA help businesses recruit and retain people with disability by offering awareness training and advice on recruitment, job matching, and job design. However, despite indications that job seekers regularly interact and form close partnerships with DETA, researchers have given limited attention to their influence. Instead, job seekers are typically examined as largely independent actors (see for an exception, Kulkarni and Scullion, 2015).

Family members. People with and without disabilities differ in the number, structure, and form of social relationships they hold (Green et al., 2005). People with disabilities tend to have lower social capital and their social network is characterised by a relatively small number of strong ties to family members (Dimakos et al., 2016). Strong ties originate not only from shared family experiences and upbringing (Baldridge, Konrad, Moore and Yang, 2017) but also from an extensive transfer of resources to the job seeker via disability related care and assistance received from family (Kulik, Cregan and Bainbridge, 2013). For instance, a son/daughter, spouse or parent may provide ongoing help with transport and paperwork to assist a job seeker with disabilities (Bainbridge and Broady, 2017). While researchers have long recognised the role of friends in assisting the search for employment (e.g., Van Hooft et al., 2005), the support 
Job seekers with disabilities 10

provided by family is likely to be particularly central to the outcomes of job seekers with disabilities (Kulik et al., 2013). Non-disabled family members are also important because they are likely to have a broader set of connections to people without disabilities. Their central location in a job seeker's network may be an important source of organisational contacts and non-disability related information. Family could also be important if they provide a pathway for conveying social norms about the desirability of employment and the employability of people with disabilities. Societal norms and opportunity structures provide a framework that influences the actions of job seekers. These social norms are distinct for job seekers with and without disabilities. People without disabilities are subject to strong pro-employment norms. In contrast, job seekers with disabilities are generally assumed to have lower capacity to undertake, and interest in, employment (McLaughlin, Bell and Stringer, 2004; Ren, Paetzold and Colella, 2008). These norms potentially shape how a family supports a job seeker, impact job search intentions, and undermine job search efficacy.

\section{Disability type and the job search process}

Theoretical models such as the disability stigmatization model (Stone and Colella, 1996) give prominence to the role of disability characteristics in shaping employment outcomes. However, this emphasis on disability type is not reflected in empirical work where organisational researchers tend to consider people with a single disability type or aggregate people with a wide range of disabilities (Baldridge et al., 2016; Dwertmann, 2016). These approaches preclude strong conclusions about the relative experience of job seekers with different disabilities. Some researchers have found though that people with disabilities experience barriers to workforce inclusion that vary by disability type. People with non-visible (versus visible) disabilities are argued to face different challenges in 
applying for jobs and undertaking interviews (Clair, Beatty and Maclean, 2005). Other researchers have compared people with mental and physical disabilities (Bainbridge, Cregan and Kulik, 2006; Ren et al., 2008; Feldman, 2004) or outlined how disability type influences co-worker acceptance (McLaughlin et al., 2004).

Organisational researchers are however yet to contrast job seekers with two major classes of disability: musculoskeletal (e.g., back injury, paralysed) and sensory (e.g., hearing, vision). Comparing the two groups is important because there are reasons to expect that they have distinct workforce experiences. First, people with sensory disabilities have poorer employment outcomes than people with other disabilities - even after controlling for severity differences (Brault, 2008). This may be because people with sensory disabilities face challenges with communication tasks that are central to almost every job in modern society. These communication barriers may contribute to their experience of significant wage discrimination (Baldwin and Choe, 2014).

Second, distinct stereotypes are held about the capabilities of people with musculoskeletal and sensory disabilities. Disability and stigmatisation research suggests that mental illnesses are viewed more negatively than sensory disabilities, and sensory disabilities more negatively than physical (Tringo, 1970; Corrigan et al., 2000; Jones et al., 1984). To illustrate, people with physical musculoskeletal disabilities (i.e., wheelchair bound) are rated higher on conscientiousness and openness/extraversion but lower on competence (Louvet, 2007). They are also believed to be courageous and highly motivated (Stone and Colella, 1996; Fichten and Amsel, 1986). In contrast, people with sensory hearing impairments are stereotyped as less able, cognitively diminished, and uninteresting (Heine and Browning, 2002; Kochkin, 2007; Parrette and Scherer, 2004; Baldridge et al., 2016). These stereotypes adversely affect hiring decisions and contribute to hiring related complaints from job seekers with sensory disabilities (Bowe, McMahon, 
Chang and Louvi, 2005). They are also internalised by people with disabilities and guide approaches to seeking jobs. For example, Goffman (1963) argued that using assistive technologies (e.g., hearing aids) identifies a person as a member of negatively evaluated group, prompting the formation of discriminatory attitudes. These attitudes may contribute to a job seeker's decision to not use a hearing aid to avoid stigma (Kochkin, 2007). This adversely affects performance in the selection process.

Third, comparing job seekers with musculoskeletal and sensory disabilities is important due to their prevalence. In Australia, $7 \%$ of the population have a disability primarily caused by musculoskeletal disorders - making these the most common chronic conditions in the country. A further $2 \%$ hold a sensory disability (ABS, 2009). A large proportion of people with musculoskeletal or sensory disabilities are also active labour market participants (Erickson, Lee and von Schrader, 2010). This implies that efforts to improve their job search experiences are of particularly high consequence to job seekers, employers, and society.

\section{METHOD}

\section{Research design and sample}

Desired sample characteristics were informed by theoretical considerations. In particular, sampling was informed by research which categorises personal and contextual features as influences on the job search process (e.g., Wanberg et al., 1996; Kanfer et al., 2001) and research which distinguishes the experiences of people with musculoskeletal and sensory disabilities (e.g., Tringo, 1970; Baldwin and Johnson, 1998; Baldridge et al., 2016). We also sought job seekers who varied on age, gender and employment status.

The sample of job seekers consisted of 25 people with musculoskeletal $(n=10)$ or sensory $(n=15)$ disabilities. Ages ranged from 24 to 60 years $($ mean $=40.5)$. Ten were 
male and 15 female. Two-thirds were currently employed and the remainder unemployed. The level of assistance required for day-to-day activities (e.g., transport, communication) ranged from 1 to 3.6 on a 10 point scale $($ mean $=1.9)$. Average time spent looking for a job ranged from 1.5 to 72 months $($ mean $=17.6)$. Average hours spent per week searching for a job ranged from 1 to $30($ mean $=12.1)$ and the average number of job applications completed per week ranged from 0 to $8($ mean $=4.2)$. Job seekers received few interview offers (range $=0-40 ;$ mean $=5.2)$.

Six additional individuals provided expert perspectives on contextual elements relevant to building an understanding of the job search environment (organisational recruitment and selection processes, support provided by government/quasi-government agencies, disability employment policy, family dynamics). Two worked as employment advisors at DETA. The third worked as a recruitment manager for a private Fortune Global 500 organisation. A fourth was an expert in Australian disability employment policy who was also vision impaired. This expert helped to ensure that our understanding of the research context and our interpretation of the data was aligned with participants. Finally, we interviewed the spouses of two job seekers to explore the family context.

\section{Procedure and data collection}

Most $(n=19)$ interviewees with disabilities were recruited with assistance of five DETA operating in the states of Victoria and New South Wales, Australia. These DETA invited job seekers to participate who were using the DETA to look for work or had used one to obtain employment in the last year. One week before the interview, DETA advisors distributed a survey to interviewees that focused on demographic and disability characteristics. Face to face interviews were conducted at the DETA. The remaining six interviewees were recruited with a snowball sampling technique to ensure that the study 
Job seekers with disabilities 14

also captured the experience of job seekers who didn't use a DETA. To obtain the snowball sample, the initial interviewees volunteered contact details of job seekers with musculoskeletal or sensory disabilities. These people were contacted by email and invited to complete the same survey and a phone interview. A contact summary sheet (Miles and Huberman, 1994) was completed after all interviews to record additional observations (e.g., volunteering and educational experiences). These notes provided context to the employment related information that interviewees supplied. Interview questions focused on personal and contextual influences on job search and were based upon variables drawn from the job search literature (e.g., Kanfer et al., 2001; Wanberg et al., 1996). Interview questions explored personal and contextual influences on job search attitudes, behaviours, intermediate outcomes, and employment outcomes. Illustrative personal influence questions included "How did your personality influence your job search?", "How did your job search change over time?" Illustrative contextual influence questions included "Can you describe the things that either positively or negatively affected your search for employment?" and "What sort of support did you receive while you looked for paid work?" We refined our interview questions with the assistance of DETA advisors to ensure the appropriateness (e.g., use of terms and concepts familiar to interviewees) and completeness of the interview protocol prior to data collection.

The six individuals who provided expert perspectives were contacted directly and interviews were undertaken face to face at their employment location (DETA advisors) or by phone (recruitment manager, employment policy expert, job seeker's partner). Open ended interviews were conducted and centred on a detailed exploration of two guiding questions: "What are the issues that contribute to successful employment of job seekers with disabilities?" and "What observations do you have about the experience of people with disabilities who are looking for work?" 


\section{Data analysis}

Thematic analysis was conducted to identify barriers and facilitators at each stage of the job search process using the NVivo qualitative data analysis package. Interview transcripts were reviewed to identify study relevant phrases. Each relevant textual example was then categorised in terms of its illustration of a stage of the job search process, or as a barrier or facilitator of job search attitudes, behaviours and outcomes. We refined our analysis by undertaking repeated comparisons of examples that had been grouped in the same category. By this process, we ensured that the assignment of examples to categories was such that categories were non-redundant, readable, general, and discriminant (O'Reilly, Chatman and Caldwell, 1991). In line with best practice (Saunders and Townsend, 2016), this analysis provided evidence for data saturation and hence the adequacy of the sample size in the form of repetition in coding examples to existing categories and the absence of new categories being created (Neuendorf, 2002). As a final step, we used a qualitative clustering approach (Miles and Huberman, 1994) to undertake an in-depth examination of the data. This involved the examination of data by sorting cases (rows) in a data matrix on the basis of a grouping variable (job search stage). Cases that were similar on a grouping variable were then compared to identify similarities and differences on other study variables (columns) (e.g., disability type, barriers, facilitators) (Neuendorf, 2002). This process helped identify connections by revealing cases with similar features.

\section{RESULTS}

\section{Barriers and facilitators affecting job seekers with musculoskeletal versus sensory disabilities}


Our results are organised in five sections that parallel the core job search process: antecedents $\rightarrow$ attitudes $\rightarrow$ behaviours $\rightarrow$ intermediate outcomes $\rightarrow$ employment outcomes $\rightarrow$ feedback. This framework organises our presentation of results that specifies barriers to, and facilitators of, progression at each job search stage. Study themes are identified as "Barriers" and "Facilitators" in Figure 1. Examples of these themes that illustrate key ideas and relationships that emerged from these data are presented in Tables 1-3. ---Place figure 1, tables 1-3 here---

Job search antecedents to job search attitudes. Social norms about the employability of people with disabilities were a major barrier to forming positive job search attitudes (Table 1). These norms were conveyed by family members in well intentioned attempts to reduce the desirability of seeking a job. For example, they downplayed the social obligation a person might feel to work and emphasised the futility of searching to protect a job seeker's self-concept from the threat of an unsuccessful search. Interactions with DETA and family members could also facilitate the development of positive job attitudes. These stakeholders enhanced job attitudes via empathetic conversations that provided an opportunity to discuss experiences, by identifying career paths, and by assisting with goal setting. For job seekers with sensory disabilities, these conversations allowed them to form specific search intentions that took into account vision restrictions. For job seekers with musculoskeletal disabilities, these stakeholders enhanced search attitudes by identifying jobs they were well suited for, and by identifying careers that allowed flexibility in how work was conducted. This information helped to counteract the social exclusionary effects of low employability norms by encouraging self-evaluation, reflection and social comparisons that enhanced confidence about seeking work. 
Job search attitudes to job search behaviours. Four barriers attenuated the positive relationship between job search attitudes and behaviours: restrictive eligibility rules for assistance programs, uncertainty about eligibility rules for assistance, difficulties in finding job opportunities, and low effectiveness of employment agencies. In contrast, support in the form of job opportunity identification, information about job accessibility, an ability to share concerns, affirmative action programs, and employment agency resources helped to translate job search attitudes into job relevant behaviours (Table 1).

Restrictive eligibility rules that limited access to assistive technologies were particularly problematic for job seekers with hearing impairments. Job seekers with vision impairments also found it especially hard to identify whether potential behaviours (e.g., volunteer work) complied with complex eligibility rules for assistance. This uncertainty led to risk averse behaviour such as declining opportunities that could help with finding a job. Accordingly, DETA played an important facilitating role by introducing job seekers to each other and encouraging them to enrol in "job clubs". These clubs were a forum for sharing concerns or job relevant experiences and helped to ensure that job seekers acted on pro-search attitudes by submitting applications. DETA were especially valuable due to their nuanced understanding of the challenges faced by a job seeker. The difficulty of finding jobs was reflected in job seekers' advocacy for affirmative action programs for people with disabilities. Furthermore, DETA and family members played a major role in identifying job opportunities for job seekers with vision impairments. For example, they improved awareness of opportunities by searching for jobs in less accessible media formats. They also helped to clarify the suitability of potential jobs by identifying the essential tasks of a position, its location, and the work climate (e.g., disability policies). This allowed a job seeker to better understand the value they could add for an employer and to pursue the most appealing jobs. Interviewees also noted the challenge of DETA 
advisors who were overworked and poorly resourced. This was a major problem for job seekers with vision impairments who relied on advisors to go out to the field and identify accessible workplaces through public transport.

Job search behaviours to intermediate job search outcomes. Four contextual features acted as barriers to intermediate search outcomes such as interview offers: disability stereotypes held by employers, job irrelevant employee requirements, difficulties preparing application materials, and difficulties accessing job interviews. By contrast, job search behaviours were more likely to lead to interview offers in the presence of high quality personal networks, alternative work arrangements, access to feedback on job applications, information sharing with other job seekers, and transportation to interviews (Table 2). Employers were described as holding unfavourable disability stereotypes as disclosing a disability dramatically reduced the chances of an interview. This barrier was somewhat alleviated by developing personal networks. In this respect, job seekers with musculoskeletal disabilities appeared to have greater success with networking attempts as the physical rehabilitation they often undertook increased their chances of meeting people outside the disability community (e.g., in gyms, parks). This physical activity had the added benefit of disconfirming the stereotype of physical limitation. A second barrier was application forms that asked for skills that were irrelevant to performing a job. These requirements (e.g., holding a driver's license) excluded many job seekers with vision impairments from being considered. Job seekers dealt with job irrelevant requirements by suggesting alternative work arrangements. Difficulties in preparing applications were particularly noted by job seekers with vision impairments who found it hard to complete online applications. For these job seekers, DETA provided critical appraisal support by checking resumes against selection criteria, giving constructive feedback with written communication via drafting and proofreading, 
and sharing knowledge about voice activated technology and software for retrieving emails and interpreting text documents. A fourth barrier for job seekers who couldn't drive was that their ability to attend an interview was often tied to public transport availability. Thus, for job seekers with vision impairments, taxi vouchers and transport that lessened the challenge of navigating to an unfamiliar interview location were especially beneficial. Additionally, barriers to attending interviews were overcome with the help of family members who provided transport and by conversations with other job seekers who shared tips for solving similar problems (e.g., transport supplied by charities, skype interviews).

Intermediate job search outcomes to employment outcomes. The likelihood that participation in interviews and assessment centres would lead to job offers was negatively affected by employer unfamiliarity with job seekers with disabilities, limited job seeker interview experience, job requirements, and workplace accessibility. In contrast, this relationship was stronger in the presence of greater educational efforts, interview preparation, information about job requirements, and access to transport (Table 2). Job seekers noted that interviewer unfamiliarity with people with disabilities curtailed the likelihood of job offers. Poor outcomes were especially likely for people with sensory disabilities as interviewers failed to distinguish between different levels of disability severity. Thus, interviews were most likely to lead to job offers when DETA contacted potential employers in advance to educate them about subsidised work accommodations (e.g., screen readers). Job seeker interviewing inexperience was a further barrier to success along with limitations in a job seeker's understanding of job requirements. DETA and family members thus played an important role by providing coaching and clarifying requirements to help inexperienced job seekers successfully navigate the interview process. Job seekers with sensory disabilities had particular difficulty in interpreting 
Job seekers with disabilities 20

verbal and non-verbal feedback provided by interviewers. They therefore benefited from practicing interview techniques with DETA and family members who ensured that feedback about interview skills was conveyed and understood. A lack of funding for supporting an employee's access to a workplace was also problematic. This was particularly felt by job seekers with vision disabilities who felt that the provision of support for a potential employee's daily commute would dramatically improve their employability.

Feedback processes. Two barriers shaped feedback processes: Job seeker attributions of access discrimination, and self-attributions of low competency (Table 3). Both increased the likelihood of giving up the search for work. However, feedback that DETA provided on job applications and interviews helped job seekers to constructively reflect on their strengths and areas for improvement. This encouragement was complemented by efforts that developed job search skills. DETA also helped job seekers to avoid unhelpful attributions by encouraging them to consider how specific aspects of a situation could be framed in a positive light. This allowed job seekers to focus on the positives and alleviated the adverse effects of unsuccessful experiences. Finally, broad based encouragement provided by family buffered job seekers from the effects of rejection and helped to maintain positive search attitudes. In contrast, when this was absent, unsuccessful experiences tended to discourage ongoing job search efforts.

\section{DISCUSSION}

Employment is central to the social inclusion. However, people with disabilities report significant barriers to obtaining paid work. The current study was designed to explore the personal and contextual features that shape this experience. By considering the role of stakeholders in shaping job search for people with sensory or musculoskeletal 
disabilities, our data have implications for theory and research. First, we extend the job search literature by focusing on a group that is rarely considered: people with disabilities. This allows attention to be drawn to understudied barriers and facilitators of the search for employment. This is important as prior job search research in the organisational literature has explored job search in relation to non-diverse samples. In particular, our consideration of the entirety of the job search process helps to reveal barriers and facilitators of what takes place before a job application is submitted. These aspects have been relatively neglected (Stone and Williams, 1997; Kulkarni and Lengnick-Hall, 2014). Thus, we know little about influences that shape job search attitudes (e.g., motivation to look for employment) or job search behaviours (e.g., preparation of high quality applications). Our findings (e.g., concerning the role of social norms on job search attitudes and eligibility rules on search behaviours) are an important starting point. However, more research on the early stages of the job search process is needed. This would provide an important complement to the current focus of the literature.

Second, our findings reveal the influence of DETA and a job seeker's family on the likelihood of obtaining paid work. The findings thus provide the groundwork for extending the job search literature in a new direction by illustrating how stakeholders convey the influence of interpersonal, institutional, policy, and societal considerations at each stage of the job search process. This allows a more complete understanding of the complex influences on a job seeker's efforts to obtain employment. Accordingly, our data underline a need to take more account of stakeholders in the design of future research. Recent work has begun to place greater emphasis on job search context (e.g., Zikic and Saks, 2009; Wanberg, 2012; Boswell et al., 2012) but further consideration of how stakeholders act as conduits for contextual influences may prove rewarding. To illustrate, our findings are notable in revealing that the same actors can both facilitate and impede 
Job seekers with disabilities 22

the search for employment. In some cases, family reduced a job seeker's commitment to looking for paid work by communicating social norms that pursuing employment was not expected. In others, they provided emotional, instrumental, informational, and appraisal support that motivated search efforts. Our findings also underline the importance of studying how job seekers' behaviours are shaped by regular interactions with DETA and family members. Future researchers might examine whether the relationships outlined in this study generalise to job seekers with other attributes (e.g., race, mature age) that are associated with unfavourable workforce experiences.

Third, our findings indicate the importance of accounting for the heterogeneity of people with disabilities. Disability researchers have noted the problems of aggregating people with different disabilities in a single study (e.g., Dwertmann, 2016). This problem has prompted a call for research that examines the influence of disability type (Kulkarni and Scullion, 2015). Our findings on the relative experience of people with musculoskeletal versus sensory disabilities validate these concerns by revealing their distinct job search experiences. We thus encourage researchers to place greater emphasis on disability characteristics in future investigations. An illustration of the importance of this is suggested by our results that reveal how mobility barriers affect job search at four points: accessing workplaces to identify job opportunities, accessing workplaces to determine suitability before submitting a job application, accessing interviews, and accessing workplace should a job be offered. These findings underline the importance of contextual features outside of the workplace that shape access to employment. This is an important complement to the literature's emphasis on issues pertaining to the selection decision, interviewer beliefs, accommodation decisions, and employer and co-worker attitudes within the workplace (Stone and Williams, 1997; Kulkarni and Lengnick-Hall, 2014). 
Practical implications. Our study allows us to identify specific points of intervention for enhancing job search outcomes. For job seekers, our data underline the importance of stakeholders in overcoming search barriers. We thus recommend that job seekers seek out DETA and family members and consider their potential as highly valuable partners in the search for work. The support of these stakeholders helped job seekers prepare applications and for interviews. It also enhanced search attitudes, buffered the effects of failure, and reinforced the benefits of successful search experiences. We especially emphasise the value of these connections for job seekers with sensory disabilities who experienced comparatively greater barriers to job search.

The results have major relevance to the employment and training agencies that support job seekers. We found that DETA was effective in shaping job seeker outcomes when they worked with employers to identify appropriate job vacancies, convey the skills of applicants, and educate about disability. These relationships provide an avenue for disconfirming disability stereotypes and encouraging disability friendly approaches to recruitment and selection. Employers and HR managers might thus draw upon the results by reviewing organisational practices to ensure they are disability inclusive. For example, HR managers might scrutinise training, evaluation, and rewards programs to ensure that interviewers are knowledgeable about the needs of applicants with disabilities. Particular consideration might be given to alternatives to inflexible online recruitment processes that were a major barrier for the vision impaired and to selection processes that contain job irrelevant criteria (e.g., a driver license requirement). HR managers might also draw upon our findings to expand the constructive feedback provided to unsuccessful candidates. Both DETA and employer interventions helped job seekers cope with and rationalise rejection. These approaches to managing unsuccessful applicants could offer significant reputational benefits given the large number of applicants who are typically unsuccessful 
Job seekers with disabilities 24

in obtaining any particular position.

The findings also have relevance to the family of job seekers with disabilities. These close relationships are a major source of emotional and instrumental support. Our study identified their influence as a communicator of employability norms, an identifier of job opportunities, and as a link to other job seekers and supportive individuals. Family are thus advised to be especially mindful that their efforts are well targeted to the needs of the job seeker.

Finally, policymakers might consider affirmative action legislation that extends coverage to people with disabilities in order to enhance their job prospects. Policymakers might also consider educational efforts that address disability employment stereotypes. Another intervention suggested by our findings is to allow job seekers the flexibility to allocate government financial support to where it is most needed (see for example, Bainbridge, Broady and Fong, 2016). We found that both products (e.g., hearing aids) and transport services removed barriers to interview performance and work accessibility. We also identified the importance of interventions that helped job seekers to overcome the setbacks encountered while looking for work. While DETA buffered the effects of rejection on job seeker self-efficacy, we consistently found that DETA were underresourced. More resources would allow them to provide a greater level and customisation of support.

Study strengths, limitations, and future research. We drew upon data from different types of job seekers (unemployed, recently employed, with a history of successfully obtaining jobs) and from people with different roles (DETA advisors, spouses, an expert on disability employment policy, a recruitment manager). However, future researchers might explore alternative data collection approaches. Data from multiple family members of each job seeker would provide a richer understanding of 
variations in barriers and support experienced by job seekers. Researchers might also consider designs that draw upon job search activity data from DETA records to complement that provided by the job seeker.

The majority of job seekers were drawn from people who interacted with DETA. This approach provided a single point of access to large group of job seekers with disabilities. This is important as the research population is geographically dispersed and hard to access. However, this approach may have influenced the sample characteristics as job seekers who register with DETA are likely to have been unemployed for a longer period. Time generally elapses between the start of unemployment and DETA registration. In our study, we addressed this by requesting that DETA advisors contact short, medium and long term unemployed for involvement in the study. Further, we used a snowball sampling approach for some job seekers to ensure that we interviewed nonDETA job seekers. Despite these efforts it remains possible that the study findings are more descriptive of the experience of longer term unemployed. Future researchers might consider alternative designs that provide greater access to new job seekers.

This study has several design features that methodologically complement prior disability research. Specifically, the design directly addresses several gaps in the literature articulated by Kulkarni and Scullion (2015). These involve a need for research on DETA that are "based in a wider range of geographies catering to various forms of disability" (Kulkarni and Scullion, 2015: 1177). In this respect, the study provides an opportunity to explore job search issues in a distinct regulatory, political, and employment context to prior research conducted in India. We also addressed a call for research that "ask[s] about the different forms of support that agencies may have given to different employee groups" (Kulkarni and Scullion, 2015: 1178) by identifying the support that is most helpful for job seekers with musculoskeletal versus sensory disabilities. Finally, a strength was our 
Job seekers with disabilities 26

efforts to capture the views of a variety of employment stakeholders. This approach addresses an expressed need for studies that elicit the views of DETA, job seekers, and employers (Kulkarni and Scullion, 2015) and contrasts favourably with current research that is characterised by a reliance on a single type of informant.

In conclusion, this study provided an opportunity to investigate the role of disability employment and training agencies, family, and disability type in shaping the experience of job seekers with disabilities. In addition, it represents a chance to examine the understudied early stages of the job search process. By exploring these issues we address a major gap at the intersection of the disability and job search literatures enriching knowledge about the barriers faced by job seekers with disabilities and revealing practical steps that can be taken to improve their employment outcomes. 


\section{REFERENCES}

ABS (2009). Disability, ageing and carers: Summary of findings (Cat. No. 4430.0), ABS, Canberra.

ABS (2012). Disability and labour force participation, 2012 (Cat No. 4433.0.55.006), Australian Bureau of Statistics, Canberra, Australia.

Ali, M., L. Schur and P. Blanck (2011). 'What types of jobs do people with disabilities want?', Journal of Occupational Rehabilitation, 21, pp. 199-210.

Araten-Bergman, T. (2016). 'Managers' hiring intentions and the actual hiring of qualified workers with disabilities', International Journal of Human Resource Management, 27, pp. $1510-1530$.

Bainbridge, H. T. J. and T. R. Broady (2017). 'Caregiving responsibilities for a child, spouse or parent: The impact of care recipient independence on employee wellbeing', Journal of Vocational Behavior, 101, pp. 57-66.

Bainbridge, H. T. J., T. R. Broady and M. Fong (2016). 'Addressing social exclusion: The role of individualized funding in facilitating employment', Journal of Business and Management, 22, pp. 23-38.

Bainbridge, H. T. J., C. Cregan and C. T. Kulik (2006). 'The effect of multiple roles on caregiver stress outcomes', Journal of Applied Psychology, 91, pp. 490-497.

Baldridge, D., A. M. Konrad, M. M. Moore and Y. Yang (2017). 'Childhood-onset disability, strong ties and employment quality', Equality, Diversity and Inclusion, 36, pp. 290-305.

Baldridge, D. A., J. E. Beatty, S. Böhm, M. Kulkarni and M. Moore (2016). 'Persons with (dis)Abilities'. In: A. Colella and E. King (eds.), The Oxford handbook of discrimination at work. UK: Oxford University Press.

Baldridge, D. C. and M. Kulkarni (2017). 'The shaping of sustainable careers post hearing 
Job seekers with disabilities 28

loss: Toward greater understanding of adult onset disability, disability identity, and career transitions', Human Relations, 70, pp. 1217-1236.

Baldwin, M. L. and C. Choe (2014). 'Wage discrimination against workers with sensory disabilities', Industrial Relations, 53, pp. 101-124.

Baldwin, M. L. and W. G. Johnson (1998). 'Dispelling the myths about work disability. New approaches to disability in the workplace'. pp. 39-61. Madison, WI: Industrial Relations Research Association.

Bandura, A. (1977). Social learning theory, General Learning Press, New York.

Bandura, A. (1986). Social foundations of thought and action: A social cognitive theory, Prentice Hall, Englewood Cliffs, NJ.

Bandura, A. (1989). 'Human agency in social cognitive theory', American Psychologist, 44, pp. $1175-1184$.

Barber, A. E., C. L. Daly, C. M. Giannantonio and J. M. Phillips (1994). 'Job search activities: An examination of changes over time', Personnel Psychology, 47, pp. 739-766.

Blau, G. (1993). 'Further exploring the relationship between job search and voluntary individual behavior', Personnel Psychology, 46, pp. 313-330.

Boswell, W. R., R. D. Zimmerman and B. W. Swider (2012). 'Employee job search: Toward an understanding of search context and search objectives', Journal of Management, 38, pp. 129-163.

Bowe, F. G., B. T. McMahon, T. Chang and I. Louvi (2005). 'Workplace discrimination, deafness and hearing impairment: The national EEOC ADA research project', Work: A Journal of Prevention, Assessment and Rehabilitation, 25, pp. 1-25.

Brass, D. J. (1985). 'Men's and women's networks: a study of interaction patterns and influence in an organization', Academy of Management Journal, 28, pp. 327-343. 
Brault, M. W. (2008). Americans with disabilities: 2005. Current population reports No. P70-117, U.S. Census Bureau., Washington, DC.

Brown, D. J., R. T. Cober, K. Kane, P. E. Levy and J. Shalhoop (2006). 'Proactive personality and the successful job search: A field investigation with college graduates', Journal of Applied Psychology, 91, pp. 717-726.

Bruyère, S. and P. James (1997). 'Disability management and the Disability Discrimination Act', Human Resource Management Journal, 7, pp. 5-17.

Burchardt, T. (2000). Enduring economic exclusion: Disabled people, income and work, Joseph Rowntree Foundation, York.

Carver, C. S. (2003). 'Pleasure as a sign you can attend to something else: Placing positive feelings within a general model of affect', Cognition and Emotion, 17, pp. 241-261.

Carver, C. S. (2006). 'Approach, avoidance, and the self regulation of affect and action', Motivation and Emotion, 30, pp. 105-110.

Cavanagh, J., T. Bartram, H. Meacham, C. Bigby, J. Oakman and E. Fossey (2016). 'Supporting workers with disabilities: A scoping review of the role of human resource management in contemporary organisations', Asia Pacific Journal of Human Resources.

Clair, J. A., J. E. Beatty and T. L. Maclean (2005). 'Out of sight but not out of mind: Managing invisible social identities in the workplace', Academy of Management Review, 30, pp. 78-95.

Corrigan, P. W., River, L. P., R. K. Lundin, K. U. Wasowski, J. Campion, J. Mathisen, H. Goldstein, M. Bergman, C. Gagnon and M. A. Kubiak (2000). 'Stigmatizing attributions about mental illness', Journal of Community Psychology, 28, pp. 91102.

Cregan, C., C. T. Kulik and H. T. J. Bainbridge (in press). 'Differences in well-being 
Job seekers with disabilities 30

among people with disabilities in paid employment: Level of restriction, gender and labour market context', Social Policy \& Administration.

Cunningham, I., P. James and P. Dibben (2004). 'Bridging the gap between rhetoric and reality: Line managers and the protection of job security for ill workers in the modern workplace', British Journal of Management, 15, pp. 273-290.

Dimakos, C., S. B. Kamenetsky, A. Condeluci, J. Curran, P. Flaherty, J. Fromknecht, M. Howard and J. Williams (2016). 'Somewhere to live, something to do, someone to love: Examining levels and sources of social capital among people with disabilities', Canadian Journal of Disability Studies, 5, pp. 130-180.

Dwertmann, D. J. G. (2016). 'Management research on disabilities: Examining methodological challenges and possible solutions', International Journal of Human Resource Management, 27, pp. 1477-1509.

Erickson, W., C. Lee and S. von Schrader (2010). Disability statistics from the 2008 American Community Survey (ACS), Cornell University, Ithaca, NY.

Feldman, D. C. (2004). 'The role of physical disabilities in early career: Vocational choice, the school-to-work transition, and becoming established', Human Resource Management Review, 14, pp. 247-274.

Fichten, C. S. and R. Amsel (1986). 'Trait attributions about college students with a physical disability: Circumplex analyses and methodological issues', Journal of Applied Social Psychology, 16, pp. 410-427.

Freeman, L. C. (1979). 'Centrality in social networks: conceptual clarification', Social Networks, 1, pp. 215-239.

Fujimoto, Y., R. Rentschler, H. Le, D. Edwards and C. E. J. Härtel (2014). 'Lessons learned from community organizations: Inclusion of people with disabilities and others', British Journal of Management, 25, pp. 518-537. 
Goffman, E. (1963). Stigma: Notes on the management of spoiled identity, Prentice-Hall, Englewood Cliffs, NJ.

Granovetter, M. S. (1973). 'The strength of weak ties', The American Journal of Sociology, 79, pp. 1360-1380.

Granovetter, M. S. (1974). Getting a job: A study of contacts and careers, Harvard University Press, Cambridge, U.K.

Green, S., C. Davis, E. Karshmer, P. Marsh and B. Straight (2005). 'Living stigma: The impact of labeling, stereotyping, separation, status loss, and discrimination in the lives of individuals with disabilities and their families', Sociological Inquiry, 75, pp. $197-215$.

Hall, J. P. and K. Parker (2010). 'Stuck in a loop: Individual and system barriers for job seekers with disabilities', Career Development Quarterly, 58, pp. 246-256.

Heine, C. and C. J. Browning (2002). 'Communication and psychosocial consequences of sensory loss in older adults: Overview and rehabilitation directions', Disability \& Rehabilitation, 24, pp. 763-773.

Ibarra, H. (1992). 'Homophily and differential returns: Sex-differences in network structure and access in an advertising firm', Administrative Science Quarterly, 37, pp. $422-447$.

Jammaers, E., P. Zanoni and S. Hardonk (2016). 'Constructing positive identities in ableist workplaces: Disabled employees' discursive practices engaging with the discourse of lower productivity', Human Relations, 69, pp. 1365-1386.

Jans, L. H., H. S. Kaye and E. C. Jones (2012). 'Getting hired: Successfully employed people with disabilities offer advice on disclosure, interviewing, and job search', Journal of Occupational Rehabilitation, 22, pp. 155-165.

Jones, E., A. Farina, A. Hastorf, H. Markus, D. Miller and R. Scott (1984). Social stigma: 
Job seekers with disabilities 32

The psychology of marked relationships, Freeman, New York.

Kanfer, R. and F. H. Kanfer (1991). 'Goals and self-regulation: Applications of theory to work settings', Advances in Motivation and Achievement, 7, pp. 287-326.

Kanfer, R., C. R. Wanberg and T. M. Kantrowitz (2001). 'Job search and employment: A personality-motivational analysis and meta-analytic review', Journal of Applied Psychology, 86, pp. 837-855.

Kochkin, S. (2007). 'Marke Trak VII: Obstacles to adult non-user adoption of hearing aids', Hearing Journal, 60, pp. 27-50.

Konrad, A. M., M. E. Moore, E. S. W. Ng, A. J. Doherty and K. Breward (2013).

'Temporary work, underemployment and workplace accommodations: Relationship to well-being for workers with disabilities', British Journal of Management, 24, pp. 367-382.

Kulik, C. T., C. Cregan and H. T. J. Bainbridge (2013). 'I feel your pain: The moderating effect of care recipient health on the relationship between work hours and care recipient and caregiver psychological outcomes', Analyses of Social Issues and Public Policy, 13, pp. 114-136.

Kulkarni, M. (2012). 'Social networks and career advancement of people with disabilities', Human Resource Development Review, 11, pp. 138-155.

Kulkarni, M. and K. V. Gopakumar (2014). 'Career management strategies of people with disabilities', Human Resource Management, 53, pp. 445-466.

Kulkarni, M. and M. L. Lengnick-Hall (2014). 'Obstacles to success in the workplace for people with disabilities: A review and research agenda', Human Resource Development Review, 13, pp. 158-180.

Kulkarni, M. and H. Scullion (2015). 'Talent management activities of disability training and placement agencies in India', International Journal of Human Resource 
Management, 26, pp. 1169-1181.

Langford, C. R., M. L. Lengnick-Hall and M. Kulkarni (2013). 'How do social networks influence the employment prospects of people with disabilities?', Employee Responsibilities and Rights Journal, 25, pp. 295-310.

Layard, R., S. Nickell and R. Jackman (1994). The unemployment crisis, Oxford University, Oxford.

Louvet, E. (2007). 'Social judgment toward job applicants with disabilities: Perception of personal qualities and competences', Rehabilitation Psychology, 52, pp. 297-303.

Manroop, L. and J. Richardson (2016). 'Job search: A multidisciplinary review and research agenda', International Journal of Management Reviews, 18, pp. 206-227.

McLaughlin, M. E., M. P. Bell and D. Y. Stringer (2004). 'Stigma and acceptance of persons with disabilities: Understudied aspects of workforce diversity', Group \& Organization Management, 29, pp. 302-333.

McPherson, M., L. Smith-Lovin and J. M. Cook (2001). 'Birds of a feather: Homophily in social networks', Annual Review of Sociology, 27, pp. 415-444.

Miles, M. B. and A. M. Huberman (1994). Qualitative data analysis: A sourcebook of new methods, Sage, Beverly Hills, CA.

Montgomery, J. D. (1991). 'Social networks and labor market outcomes: toward an economic analysis', The American Economic Review, 81, pp. 1408-1418.

Neuendorf, K. A. (2002). The content analysis guidebook, Sage, Thousand Oaks, CA.

O'Reilly, C. A., J. Chatman and D. F. Caldwell (1991). 'People and organizational culture: A profile comparison approach to assessing person-organization fit', Academy of Management Journal, 34, pp. 487-516.

Osborn, D. P. (1990). 'A reexamination of the organizational choice process', Journal of Vocational Behavior, 36, pp. 45-60. 
Job seekers with disabilities 34

Parrette, P. and M. Scherer (2004). 'Assistive technology use and stigma', Education and Training in Developmental Disabilities, 39, pp. 217-226.

Paul, K. I. and K. Moser (2009). 'Unemployment impairs mental health: Meta-analyses', Journal of Vocational Behavior, 74, pp. 264-282.

Petner-Arrey, J., A. Howell-Moneta and R. Lysaght (2016). 'Facilitating employment opportunities for adults with intellectual and developmental disability through parents and social networks', Disability and Rehabilitation, 38, pp. 789-795.

Potts, B. (2005). 'Disability and employment: Considering the importance of social capital', Journal of Rehabilitation, 71, pp. 20-25.

Ren, L. R., R. L. Paetzold and A. Colella (2008). 'A meta-analysis of experimental studies on the effects of disability on human resource judgments', Human Resource Management Review, 18, pp. 191-203.

Richards, J. and K. Sang (2016). 'Trade unions as employment facilitators for disabled employees', International Journal of Human Resource Management, 27, pp. 16421661.

Ryan, D. J. (2011). Job search handbook for people with disabilities, JIST Works, U.S.A.

Saks, A. M. (2005). 'Job search success: a review and integration of the predictors, behaviors, and outcomes'. In: S. D. Brown and R. W. Lent (eds.), Career development and counseling: Putting theory and research to work. pp. 155-179. Hoboken, NJ: John Wiley.

Saunders, M. N. K. and K. Townsend (2016). 'Reporting and justifying the number of interview participants in organization and workplace research', British Journal of Management, 27, pp. 836-852.

Smith, S. S. (2000). 'Mobilizing social resources: Race, ethnic, and gender differences in social capital and persisting wage inequalities', Sociological Quarterly, 41, pp. 509- 
537.

Soelberg, P. O. (1967). 'Unprogrammed decision making', Industrial Management Review, 8, pp. 19-29.

Song, Z., C. Wanberg, X. Niu and Y. Xie (2006). 'Action-state orientation and the theory of planned behavior: A study of job search in China', Journal of Vocational Behavior, 68, pp. 490-503.

Stone, D. L. and A. Colella (1996). 'A model of factors affecting the treatment of disabled individuals in organizations', Academy of Management Review, 21, pp. 352-401.

Stone, D. L. and K. J. Williams (1997). 'The impact of ADA on the selection process: Applicant and organizational issues', Human Resource Management Review, 7, pp. 203-231.

Szymanski, E. M. and R. M. Parker (2003). Work and disability: Issues and strategies in career development and job placement, PRO-ED, Austin, TX.

Tajfel, H. and J. C. Turner (1979). 'An integrative theory of intergroup conflict'. In: W. G. Austin and S. Worchel (eds.), The social psychology of intergroup relations. pp. 3347. Monterey, CA: Brooks-Cole.

Tringo, J. L. (1970). 'The hierarchy of preference toward disability groups', The Journal of Special Education, 4, pp. 295-306.

Van Hooft, E. A. J., M. P. Born, T. W. Taris and H. Van der Flier (2005). 'Predictors and outcomes of job search behavior: The moderating effects of gender and family situation', Journal of Vocational Behavior, 67, pp. 133-152.

Villanueva-Flores, M., R. Valle and M. Bornay-Barrachina (2017). 'Perceptions of discrimination and distributive injustice among people with physical disabilities: In jobs, compensation and career development', Personnel Review, 46, pp. 680-698.

Wanberg, C. R. (2012). 'The individual experience of unemployment', Annual Review of 
Job seekers with disabilities 36

Psychology, 63, pp. 369-396.

Wanberg, C. R., G. Basbug, E. A. Van Hooft and A. Samtani (2012a). 'Navigating the black hole: Explicating layers of job search context and adaptational responses', Personnel Psychology, 65, pp. 887-926.

Wanberg, C. R., L. M. Hough and Z. Song (2002). 'Predictive validity of a multidisciplinary model of reemployment success', Journal of Applied Psychology, 87, pp. $1100-1120$.

Wanberg, C. R., J. D. Watt and D. J. Rumsey (1996). 'Individuals without jobs: An empirical study of job-seeking behavior and reemployment', Journal of Applied Psychology, 81, pp. 76-87.

Wanberg, C. R., J. Zhu, R. Kanfer and Z. Zhang (2012b). 'After the pink slip: Applying dynamic motivation frameworks to the job search experience', Academy of Management Journal, 55, pp. 261-284.

Wanberg, C. R., J. Zhu and E. A. J. Van Hooft (2010). 'The job search grind: Perceived progress, self-reactions, and self-regulation of search effort', Academy of Management Journal, 53, pp. 788-807.

Waverijn, G., M. Heijmans and P. P. Groenewegen (2017). 'Neighbourly support of people with chronic illness; is it related to neighbourhood social capital?', Social Science \& Medicine, 173, pp. 110-117.

WHO (2011). 'World report on disability'. Geneva, Switzerland: World Health Organization.

Zikic, J. and A. M. Saks (2009). 'Job search and social cognitive theory: The role of career-relevant activities', Journal of Vocational Behavior, 74, pp. 117-127. 
Table 1: Barriers and facilitators of job search attitudes and behaviours - themes and illustrative quotes

\section{Barriers to positive job search attitudes}

Social norms about the employability of people with disabilities: "But it [job search self-efficacy] is still low, because there's one girl at my current job that says I'll 'never get another job because of my disability' and 'you do realise that even though they won't admit it they will say you didn't get the job because someone else was more qualified. They just can't say you didn't get the job because of the disability'” [I12: Paralysed]

Barriers to effective job search behaviours

Restrictive eligibility rules for assistance: "It's very important that I have hearing aid for a job or to gain employment. I have a healthcare card, but they've said in the centre I have to actually pay for a hearing aid myself. I know that the hearing aids are very expensive. I can't actually afford them. Plus I need a hearing aid for the truck licence. It's important, but at the moment I don't actually have hearing aids." [19: Vision impaired] Uncertainty about assistance eligibility rules: "They don't give you the information. You have to find it out yourself. You don't know what to ask. I said to them, I'm going to volunteer. They said you can't do that. I said I wish you had told me that, because there are very hard restrictions and if you step over them you get into big trouble." [I19: Back injury]

Difficulties in finding jobs: "They tell me to apply for jobs straight off the internet. But the success rate of looking for jobs that way is very low. Being older and having a disability makes the success of that almost... it doesn't mean it's not going to happen, but it is the long way around." [I18: Vision impaired]

Employment agency effectiveness: "Last year before I got this job, I was very, very low in esteem. Especially after being stuffed around by the disability employment networks." [I12: Paralysed]

\section{Facilitators of positive job search attitudes}

Empathetic conversations: "My family. I have a good doctor and a good psychologist, and [DETA advisor]. They realise there's a lot of emotional impact that goes into looking for work or working in a workplace that isn't so accessible for me and they're very supportive." [I7: Hearing impaired]

Career path identification: My parents said, 'Well, you wanted to go to university. So why don't you still go? Do a broad-based Bachelor of Arts because that will give you a taste of a lot of things. Then you might find out what you like.' From there, I did communication and psychology and it gave me a taste of what I wanted to do... I had to do something office-based because I knew I couldn't go out and about because I didn't drive. I needed something that was steady, that I was going to the same place all the time so that the environment was always the same. I knew that I needed to do something where I could use vision substitution technology." [I13: Vision impaired] Goal setting: "The psychologist would say to me, look what do you want to do, and I'd say 'I've had a terrible experience', and the psychologist would say, 'Yes, of course'. So the psychologist asked me to write down my wish list and then think about how I could achieve those things. Write down what I'm good at and also what I'm not so good at and then look for a job that suits my skills, strengths and not so much my weaknesses. The psychologist has told me to focus on what I can do, not what I can't do." [I7: Hearing impaired]

\section{Facilitators of effective job search behaviours}

Affirmative action programs: "If we could have an affirmative action program in some way, I think that would be really quite helpful." [I13: Vision impaired]

Ability to share concerns: "You've got your [DETA] contact here, you come in, you can actually speak to them face to face and they know what you're going through because they deal with other people in the same boat. So for me that's the best part of it all is being able to actually come in and just speak to someone and not have to worry about what you say because they understand where you're coming from." [I11: Impaired in four limbs]

Job opportunity identification: "I had my husband and my daughter reading the local newspaper for me." [125: Vision impaired]

Information about job accessibility: "In the UK they've adopted a system where they started categorising jobs. They've got a tick system. So if it's got four ticks it might be fully accessible to someone using JAWS. That's the issue, finding the workplace." [I18: Vision impaired]

Employment agency resources: "...they only have one employment engagement consultant, which to me, one person out in the field probably isn't enough. For 120 clients, it isn't enough ...there's only so much an employment consultant and the training support officer person can do." [I18: Vision impaired] 


\section{Barriers to intermediate job search outcomes}

Disability employment stereotypes held by employers: "A lot of roles rely

on people to use their back. Even if it doesn't, there's the assumption that people with a back injury are going to struggle to do the work." [I2: DETA advisor 2]

Job irrelevant employee requirements: "They just assume that I'm not going to be able to do a job and they always say you've got to have a driver's license. Plenty of people [are] knocked back for jobs because they don't have a driver's licence. For the odd occasion that somebody might drive somewhere. Their expectation is even to get to a day of training that you would drive." [I13: Vision impaired]

Preparing application materials: "I put in quite a few CVs but I didn't get a lot of jobs. That was when I was trying to do it on my own. That was difficult because you then start to think it's never going to happen." [I14: Vision impaired]

Accessing interviews: "If I have a job interview there's a lot of planning because I need to find out the public transport route as I don't drive. Then I've got to figure out the walking routes." [I16: Vision impaired]

\section{Barriers to employment outcomes \\ Employer unfamiliarity with job seekers with disabilities: "So when I came} in and I didn't need a cane, they are going, 'oh you're not blind'. The employer said to me... 'But you don't have a guide dog'." [I15: Vision impaired]

Limited job seeker interview experience: "When I have interviews that does give you some confidence because people are prepared to even talk to you and think that you might have a chance of getting the job. So that does help from that initial feeling in the beginning of 'I can't do this. This is never going to work."' [I14: Vision impaired]

Knowledge of job requirements: 'I'll write the application, I'll send it. Then I have to go through the interview, which has its own elimination processes. If I have a chance of getting the job then there's also the equipment. Whether it's going to be accessible." [I16: Vision impaired] Workplace accessibility: "The location. If that's going to be accessible by public transport. Those are the main problems." [I16: Vision impaired]

\section{Facilitators of intermediate job search outcomes}

Personal networks: "I meet a lot of people at the gym... we network a lot and they've got a lot of respect for what we've achieved in spite of our health." [I12: Paralysed]

Alternative work arrangements: "Hearing and vision, even though they're sensory disabilities, rather than physical, I think there has been a big shift in regards to their success rates, given the technology that's now available for them. They previously were highly stigmatised."[I2: DETA advisor 2]

Feedback on application materials: ““'[DETA] consultants will look at your key selection criteria your resume and your application letters. Being vision-impaired, presentation isn't easy. So having someone who can see, to look at your presentation documents, whether your line spacings are good, margins are good, whether you haven't got too big a font, too small a font. It's really vital to have someone to proofread your documents." [I18: Vision impaired]

Information sharing with other job seekers: "Having good networks is very important. You must know other blind people because the problems you encounter, somebody else encountered." [I13: Vision impaired]

Transportation to interviews: "I wouldn't have got to the [interview] appointment without somebody driving me there or catching a taxi." [I25: Vision impaired]

\section{Facilitators of employment outcomes}

Educating employers: "It didn't matter how many jobs he went for, as soon as they saw him the stopped it. So we [DETA] got an employer and we went and warned them and we did all our homework about how hard he'd tried to get his truck license, and finally yes, he started on Monday. When you speak to employers individually, most of them can be quite tolerant and when you probe a bit deeper, they realise that there's nothing to be scared of." [I1: DETA advisor] Job interview preparation: "I ask my candidates to write a sentence that explains the task and provides a little bit of insight or paints a picture about the environment they work in and the task that they did. If there's a question around performing a task that might require an adaptive technology, being able to answer those sorts of questions [helps]" [I2: DETA advisor 2] Clear and accessible information about job requirements: "The [DETA] consultant might go out into the field and say, 'This job is accessible. You think you can do it? We've checked out it's in your skill level. To get there there's not too many dangerous roads, the workplace is reasonably accessible, and we can hook up JAWS screen reading software.' But it's not just applying and rocking in. Often with blindness there are difficulties using technology and interacting with other people in the workplace and attitudes to disability. It's a complex area." [I18: Vision impaired]

Transportation to job: "I don't think there's any support with transport and work-related transport, but it would make jobs more accessible if there was funding for taxis and that sort of thing. There is [funding for] work access, but they only deal with equipment." [I16: Vision impaired] 
Table 3: Barriers and facilitators of feedback processes - themes and illustrative quotes

Barriers to positive feedback processes
Job seeker attributions of access discrimination: "The confidence went a
bit down because I started to question all sorts of reasons why I kept
getting no's. Is it because they know that I have a vision impairment? I
just started to criticise myself or analyse myself and think why would
they say no? If I have the experience that they're looking for, why else
would they say no? Is it because I have differences that eliminate me?"
[I16: Vision impaired]
Job seeker self-attributions of low competency: "Oh it [job search self-
efficacy] was definitely going down. It was just through the lack of
response to applications and in my initial application I did not
communicate any disability. I waited till the interview stage to actually
communicate that. So it was an even playing ground for me and all other
candidates. But just still to hear nothing was very... I was just like
everybody else applying for a job and still hearing nothing. That's before
I even got to tell them that I've got a disability." [I25: Vision impaired]

Facilitators of positive feedback processes

Constructive feedback: "If you don't have a successful interview and it's something that you think maybe it's yourself, you can always come up here [DETA name] and speak to your case worker and you can say, 'This is what happened. Did I do the right thing?" [I11: Impaired in four limbs]

Job search skill development: "At first I got a bit discouraged but then I started working through that, working with different groups, like [DETA name], just learning to refine my interview technique. I got more self-confident with myself as I know I could talk in an interview. It dipped down but it started working up again. This time confidence, born of experience, rather than just the assumption that everything would work out." [I15: Vision impaired]

Framing of outcomes: "The support of the [DETA] network definitely made the difference and they keep you going. They keep you positive. They say no, don't worry, another one will come up here. I remembered one time I was feeling really despondent and one said to me, 'So how many

CVs have you put out?' I think it was something like eight and she said 'And how many interviews have you had?' I said I've had six. She said, 'Well you know a lot of people could have hundreds of interviews and don't even get a reply.' That is the kind of thing which you don't see that if you're in it yourself." [I14: Vision impaired]

Personal encouragement: "Before it was not like that. I would cry and everything was terrible and my family would say, 'It's okay if you don't get this job, it doesn't matter. You know, a lot of people fail. It's not just you and you can just try again.' Because prior I think everything was terrible. I didn't have a job, it was like my life was over, but my family and friends have helped me think more positively." [17: Hearing impaired] 
Figure 1: Job search barriers and facilitators for people with disabilities

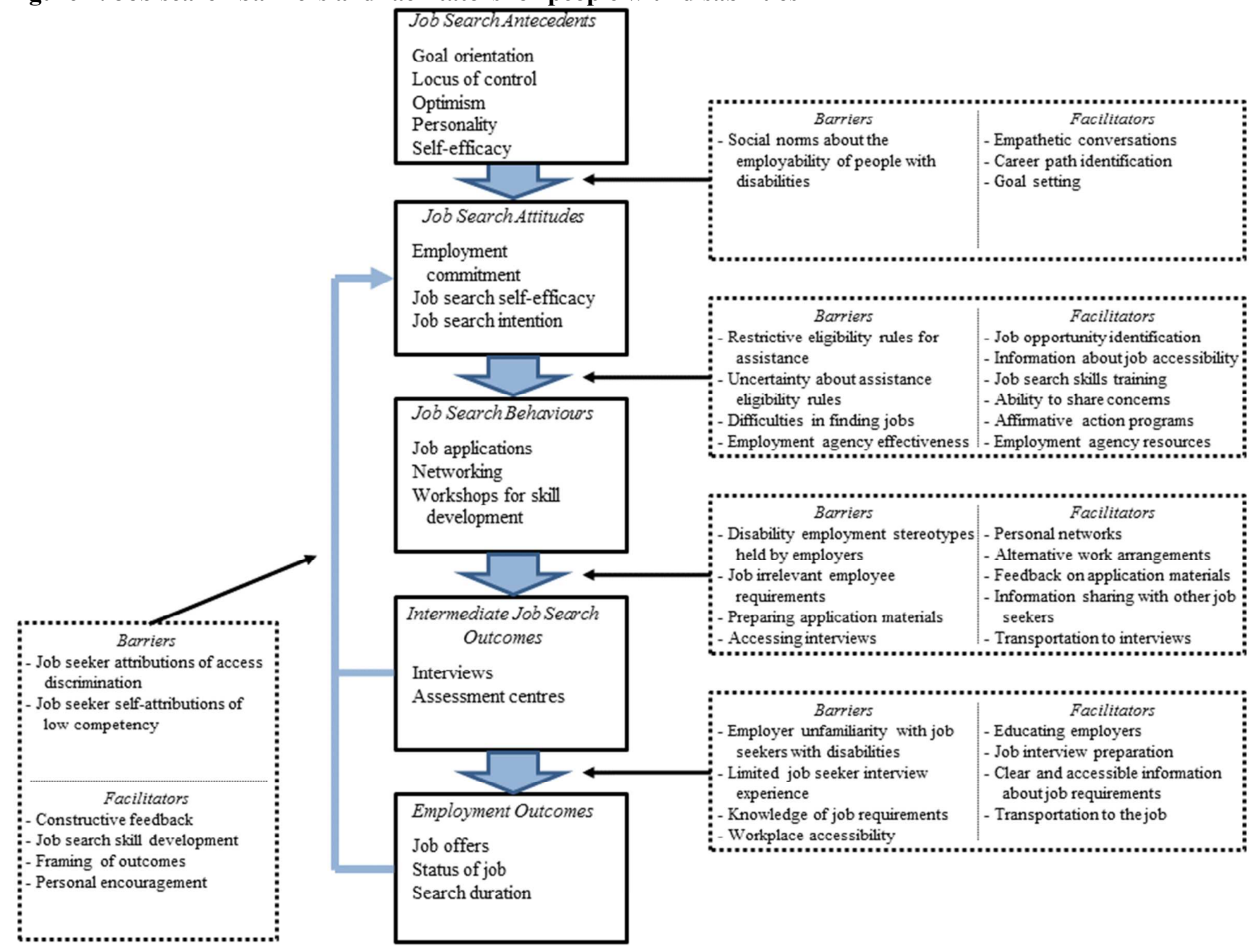




\section{British Journal of Management - Manuscript ID BJM-17-035.R2}

\section{Response to Editor}

We have revised the paper as suggested by Reviewer 1 and 2.

Concerning Reviewer 1's comments, we now cite the three suggested studies in the introduction (pages 2-3) and we provide several examples to illustrate specifics of the data collection process as recommended.

In relation to Reviewer 2's comments, we have attended to the specific suggestions made for improving the manuscript's clarity and flow with the exception of Reviewer 2's suggestion that we add a citation to Konrad, Yang and Maurer (2016). Our reading of this article suggested that the study, while interesting, was more focused on exploring features of the organisational context that predicted the utilisation of diversity and equality management systems (DEMS). This issue is somewhat distinct from the main arguments developed in our manuscript. We therefore do not introduce this additional content so as to not distract readers from the primary themes covered by our study.

Finally, we have made some minor editorial corrections to the manuscript to enhance its readability. 